\title{
Introduction of More Editorial Board Members and New Journal of American Board of Family Medicine Features
}

In an ongoing effort to acquaint our readers with primary care experts serving on the editorial board that advises and serves the fournal of the American Board of Family Medicine ( $7 A B F M)$, we are honored to introduce Kenneth Fink, Dwenda Gjerdingen, Helen McIlvain, and Donald Pathman.

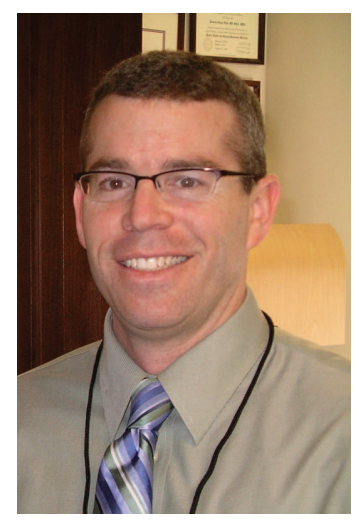

Kenneth S. Fink, MD, MGA, MPH

Kenneth S. Fink, MD, MGA, MPH, is currently the Hawaii State Medicaid Director. He previously worked as Chief Medical Officer for the Centers for Medicare and Medicaid Services Region 10 and as Director of both the US Preventive Services Task Force and the Evidence-Based Practice Centers programs at the Agency for Health Care Research and Quality. Dr. Fink was a Robert Wood Johnson Clinical Scholar, Kerr White Visiting Scholar, and Excellence in Government Fellow. He attended Haverford College, received combined Medical Doctor and Master of Government Administration degrees from the University of Pennsylvania, and was awarded a Master of Public Health degree from the University of North Carolina. He completed residencies in family medicine at the University of Washington and preventive medicine at the University of North Carolina. Dr.

Conflict of interest: The authors are editors of the $7 A B F M$.
Fink was awarded the status of Fellow by both the American Academy of Family Physicians and the American College of Preventive Medicine.

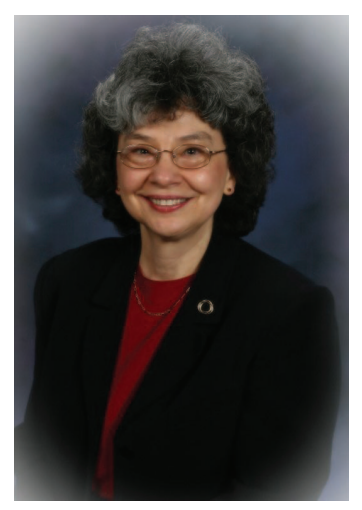

Dwenda Gjerdingen, MD, MS

Dwenda Gjerdingen, MD, MS, is a professor in the Department of Family Medicine and Community Health at the University of Minnesota. She has more than 2 decades of experience and productivity in women's health research, with an emphasis on postpartum health, particularly postpartum depression. She most recently tested a stepped collaborative care intervention for postpartum depression. As a faculty member at the St. Joseph's Family Medicine Residency Program in St. Paul, Minnesota, she also teaches residents in inpatient and outpatient settings, mentors residents in research, and maintains an active private practice. Dr. Gjerdingen is married, has 2 adult sons, and enjoys playing piano and autoharp.

Helen E. McIlvain, PhD, is Professor and Director of Research in the Department of Family Medicine at the University of Nebraska Medical Center (UNMC). She has been at UNMC since 1981 and in the Department of Family Medicine since 1993. Her $\mathrm{PhD}$ is in Counselor Education from Kansas State University. Dr. McIlvain's activities primarily involve supervising and participating in research 


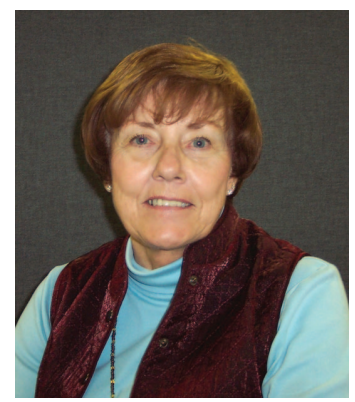

Helen E. McIlvain, PhD

with the 6 other researchers in the department, mentoring other research faculty across campus, and seeing a few patients each week. Her research interests and expertise include smoking cessation, practice systems change, physician/patient communication about lifestyle change, and qualitative research.

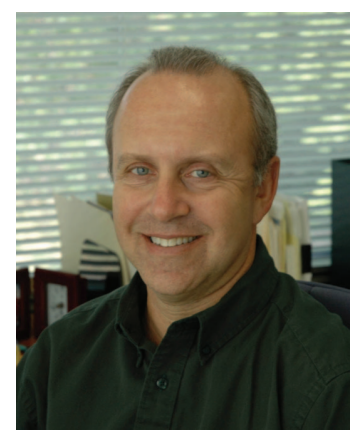

Donald Pathman, MD, MPH

Dr. Pathman is Research Director and Professor of Family Medicine at the University of North Carolina at Chapel Hill (UNC), and Director of the Program on Health Professions and Primary Care at the UNC Cecil G. Sheps Center for Health Services Research. He is Co-Editor of Education for Health and directs UNC's National Research Service Award Primary Care Research Fellowship. Dr. Pathman's principal research interests are in the areas of health workforce approaches and evaluations, access to care for rural and at-risk populations, racial-ethnic disparities in care, and research methods in primary care.

\section{Author Data Center Now Available for Corresponding Authors}

The Author Data Center allows corresponding authors to view web usage and citation information for their published article. Usage information from the $7 A B F M$ website (www.jabfm.org) is updated monthly and citation information is updated when it becomes available. Only corresponding authors will be able to access information specific to their articles. An e-mail will be sent to the corresponding author with directions on how to access this feature. In addition, the Author Data Center contains links to sign up for email alerts and view the most frequently read and cited articles in the $7 A B F M$, which are updated monthly by HighWire Press.

\section{Social Bookmarking Added to JABFM Website}

Our new social bookmarking feature allows users to organize their favorite articles and URLs in one web-based location. Social boomarking also provides the ability to search other users' bookmarks. Links to the supported social bookmarking sites can be found in the content box to the right or at the bottom of each article. This feature currently supports Connotea, CiteULike, Del.icio.us, Digg, Reddit, and Technorati. Please note that you must have an account with one of these social bookmarking sites to bookmark $7 A B F M$ articles.

\section{New Feature: Guest Physician Commentaries}

We are excited to announce a new $7 A B F M$ feature, in which a practicing family physician writes very brief commentaries on 2-3 original research articles published in the same issue. In this first such feature, James Calvert, MD, reacts to 3 research reports from PBRNs. ${ }^{1}$ The goal of this feature is to draw readers into research articles and to understand the significance of research to the practice of family medicine. These commentaries will provide personal reactions such as practical comments as to how the study might be useful for clinical practice.

We are also developing a cadre of family physicians interested in serving as guest commentators. If you are interested, e-mail your curriculum vitae to Phillip Lupo, Senior Editorial Assistant at jabfm@med.wayne.edu.

Phillip Lupo, MLIS

Anne Victoria Neale, $\mathrm{PhD}, \mathrm{MPH}$

Marjorie A. Bowman, MD, MPA

\section{Reference}

1. Calvert J. Guest family physician commentaries. J Am Board Fam Med 2009;22(4):352. 